\title{
What Interval Characteristics Make a Good Categorical Disease Assessment Scale?
}

\author{
Kuo-Szu Chiang, Shih-Chia Liu, Clive H. Bock, and Tim R. Gottwald
}

First author: Division of Biometrics, Department of Agronomy, National Chung Hsing University, Taichung, Taiwan, 402; second author: Surveillance and Research Division, Health Promotion Administration, Ministry of Health and Welfare, Taiwan, 403; third author: U.S. Department of Agriculture-Agricultural Research Service (USDA-ARS)-SEFTNRL, 21 Dunbar Rd., Byron, GA 31008; and fourth author: USDA-ARS-USHRL, 2001 South Rock Road, Fort Pierce, FL 34945.

Accepted for publication 16 January 2014.

\begin{abstract}
Chiang, K.-S., Liu S.-C., Bock, C. H., and Gottwald, T. R. 2014. What interval characteristics make a good categorical disease assessment scale? Phytopathology 104:575-585.

Plant pathologists most often obtain quantitative information on disease severity using visual assessments. Category scales have been used for assessing plant disease severity in field experiments, epidemiological studies, and for screening germplasm. The most widely used category scale is the Horsfall-Barratt (H-B) scale, but reports show that estimates of disease severity using the H-B scale are less precise compared with nearest percent estimates (NPEs) using the 0 to $100 \%$ ratio scale. Few studies have compared different category scales. The objective of this study was to compare NPEs, the H-B midpoint converted data, and four different linear category scales (5 and $10 \%$ increments, with and without additional grades at low severity $[0.1,0.5,1.0,2.0,5.0,10.0,15.0$,

$20.0 \ldots 100 \%$, and $0.1,0.5,1.0,2.0,5.0,10.0,20.0,30.0 \ldots 100 \%$, respectively]). Results of simulations based on known distributions of disease estimation using the type II error rate (the risk of failing to reject $\mathrm{H}_{0}$ when $\mathrm{H}_{0}$ is false) showed that at disease severity $\leq 5 \%$, a $10 \%$ category scale had a greater probability of failing to reject $\mathrm{H}_{0}$ when $\mathrm{H}_{0}$ is false compared with all other methods, while the H-B scale performed least well at 20 to $50 \%$ severity. The 5\% category scale performed as well as NPEs except when disease severity was $\leq 1 \%$. Both the 5 and $10 \%$ category scales with the additional grades included performed as well as NPEs. These results were confirmed with a mixed model analysis and bootstrap analysis of the original rater assessment data. A better knowledge of the advantages and disadvantages of category scale types will provide a basis for plant pathologists and plant breeders seeking to maximize accuracy and reliability of assessments to make an informed decision when choosing a disease assessment method.
\end{abstract}

Plant pathologists most often obtain quantitative information on disease severity using visual assessments. Disease severity (the proportion of a plant unit diseased) data are widely used for predicting yield loss, monitoring and forecasting epidemics, in disease surveys and for assessing crop germplasm for disease resistance, and for understanding fundamental biological processes including coevolution (10). The assessments of disease severity are often made using a category scale rather than directly estimating percent disease $(10,34)$. The most widely used category scale is the Horsfall-Barratt (H-B) scale (24), but empirical studies have suggested that category-based scales are no better (and sometimes perhaps inferior) when compared with direct estimation to the nearest percent for assessing severity $(6,18$, $31,32,34,43)$.

Simulation modeling has been used to compare different disease assessment scales (7). The results from that study indicated the H-B category scale was never better than nearest percent estimates (NPEs) for comparing treatments and its use could result in less precise data, which can lead to a greater risk of a type II error. The simulation study was based on field-collected data from citrus canker-infected grapefruit leaves $(8,9)$ with actual disease severity over the range 0 to $50 \%$ leaf area diseased.

Corresponding author: C. H. Bock; E-mail address: clive.bock@ars.usda.gov

* The $\boldsymbol{e}$-Xtra logo stands for "electronic extra" and indicates that the online version contains one supplementary figure.

http://dx.doi.org/10.1094/PHYTO-10-13-0279-R

This article is in the public domain and not copyrightable. It may be freely reprinted with customary crediting of the source. The American Phytopathological Society, 2014.
Bock et al. (7) showed that over the severity range from 20 to $50 \%$ the $\mathrm{H}-\mathrm{B}$ scale had a greater risk of committing a type II error (the probability of failing to reject the null hypothesis, $\mathrm{H}_{0}$ when $\mathrm{H}_{0}$ is false) compared with NPEs, and the standard deviations of the H-B scale data deviated from that of the original rater standard deviation over this range.

In an earlier study, Hartung and Piepho (20) simulated assessment based on known distributions of disease severities to compare three different rating scale methods; the 0 to $100 \%$ ratio scale (NPEs), a 5\% step scale, and an ordinal 9-point rating scale. The methods were compared using mixed model analysis, and the results suggested that a 5\% step was acceptable compared with the 0 to $100 \%$ scale. Previously, rater estimates based on category scales of different types have been compared with either image analysis values (43) or to other category scales or percent estimates of disease $(14,16,44)$. Statistical differences in means separation or in analysis of the relationship to yield invariably showed that category scales differed, and invariably gave different results to visual estimates or image-analyzed measurements of the percent area diseased.

Based on the results in these studies and others, how can we test different scales to ascertain their suitability for specific disease assessment needs so as to maximize accuracy and reliability and minimize the risk of type II errors? Also, will it be sufficiently sensitive to the range of disease severity likely to be encountered (27-29)? These questions are of fundamental importance in choosing the best method to assess disease. Using empirically obtained data from assessment of the severity of Phomopsis symptoms on strawberry leaves, Nita et al. (32) proposed that a category scale with $5 \%$ increments (with additional grades to cover severity $<5 \%$ ) provided estimates that were more 
accurate and precise compared with those obtained using the H-B scale. Nutter and Esker (34) also presented results using the just noticeable difference and found that direct visual estimates were superior to the H-B scale. Furthermore, considering many diseases cause low severity, it is important to design a category scale that maintains the sensitivity to disease over the low end of the disease severity spectrum to help prevent overestimation, which can be a problem in estimating disease at severities $<10 \%(10,41)$.

Additionally, Hau et al. (21) demonstrated that characteristics of the distribution of diseased leaves in the population and the number of classes in a disease scale affected the accuracy of the estimate of mean disease severity. Thus, the mean disease severity of a population will affect the performance of different category scales. Low mean disease severity is often found in the field among treatments (28), and thus it is pertinent to investigate whether error at low severity is inherent in certain scales, and if so what are the scale characteristics to avoid?

Although Kranz $(27,29)$ and Hau et al. (21) discuss and explore how to design category scales in relation to disease severity distributions, to date there have been few studies which compared different category scales, and those empirical studies that have compared multiple category scales often did not have accurately measured values for the actual disease severity (for example, Slopek [42] used a visual raters' estimate to compare category scales). The objective of this study was to directly compare the performance of different scales based on a known disease assessment distribution from estimates of actual values and over a range of disease severity. For the comparisons, six scales with different category characteristics were compared.

According to the result of this study, we believe that a better knowledge of the advantages and disadvantages of category scale types will provide plant pathologists and plant breeders seeking to maximize accuracy and reliability of assessments with an informed choice of disease category scales for making better disease assessments.

\section{THEORY AND APPROACHES}

Disease assessment data and disease assessment distribution. The disease assessments by three different raters and the actual (also known as 'true') disease values used in this study were the same as in previously reported work $(8,9)$. The original data were based on a sample of 210 citrus canker (Xanthomonas citri subsp. citri)-infected grapefruit leaves and encompass (i) measurements of the actual disease severity on a leaf-by-leaf basis using image analysis (ASSESS; The American Phytopathological Society, St. Paul, MN) and (ii) rater NPEs of disease severities for each of the 210 leaves on two separate occasions. Six different disease assessment scales were compared in this study. The characteristics of the assessment scales were as follows.

1. NPEs, disease estimated by the rater to the nearest $1 \%$.

2. The H-B scale (24).

3. A linear category scale ( $5 \%$ increments).

4. A linear category scale ( $10 \%$ increments).

5. An amended $5 \%$ category scale with additional grades at low severity $(0.1,0.5,1.0,2.0,5.0,10.0,15.0,20.0 \ldots 100 \%)$.

6. An amended $10 \%$ category scale with additional grades at low severity $(0.1,0.5,1.0,2.0,5.0,10.0,20.0,30.0 \ldots 100 \%)$.

Comparing assessment methods. In order to compare the different assessment methods, two approaches were employed. First, we tested whether there was an effect of different assessment methods on hypothesis testing (7), and second, we utilized a mixed-effects model to test for effects of different assessment methods $(20,25,39)$. These studies evaluated the consistency and reliability of a measurement across conditions by using a mixed model analysis. Finally, to further verify the results, a bootstrap resampling based on the data set $(8,9)$ was performed to generate simulated data.
Hypothesis testing. Initially we followed the procedures of a previous simulation study (7) to compare the performance of each of the six assessment methods. Assuming two treatments, treatment $\mathrm{A}$ and $\mathrm{B}$, are applied to developing epidemics, the disease severity distribution of treatment $\mathrm{A}$ has mean $\mu_{\mathrm{A}}$ and treatment $\mathrm{B}$ has mean $\mu_{\mathrm{B}}=\mu_{\mathrm{A}}+\mu_{\Delta}$, where $\mu_{\Delta}$ represents the difference between the means of the two severity distributions. The standard deviations $(\varphi)$ of the disease severity distributions of treatment $\mathrm{A}$ and $\mathrm{B}$ are assumed to be equal. The notation follows that of Bock et al. (7); but a truncated-normal distribution, rather than a normal distribution, was assumed for each treatment because the actual severities cannot be negative values.

As previously described (7), the mean rater estimated severity, $\mu_{\text {rater }}$, was regarded as a linear function of the actual severity, $Y_{\text {actual: }}$ :

$$
\mu_{\text {rater }}=\theta Y_{\text {actual }}
$$

where $\theta$ equals 1 , and a hyperbolic function described the relationship between the standard deviation $(\sigma)$ of the rater mean NPE and actual disease:

$$
\sigma=\left(\alpha Y_{\text {actual }}\right) /\left(\beta+Y_{\text {actual }}\right)
$$

Based on the results of Bock et al. (7), $\alpha$ and its standard deviation are 19.08 and 3.19, respectively; and $\beta$ and its standard deviation are 29.65 and 9.33 , respectively. Furthermore, the frequency of NPEs of specific actual disease severities by raters was assumed to follow a lognormal distribution. That is,

$$
y_{i} \sim \operatorname{Lognormal}\left(\mu, \rho^{2}\right)
$$

Here,

$$
\mu=\ln \left(\mu_{\text {rater }}\right)-\frac{1}{2} \ln \left[1+\left(\frac{\sigma}{\mu_{\text {rater }}}\right)^{2}\right]
$$

and

$$
\rho=\sqrt{\ln \left[1+\left(\frac{\sigma}{\mu_{\text {rater }}}\right)^{2}\right]}
$$

When a value from the treatment was simulated, it represented the actual severity $\left(Y_{\text {actual }}\right)$. Based on the rater estimate parameters described (7), the rater estimated severity $\left(\mu_{\text {rater }}\right)$ and standard deviation $(\sigma)$ were acquired through equations 1 and 2 . Thus, a simulated value based on the distribution of rater estimated disease severities was obtained using equations 3,4 , and 5 . To simulate observations using the H-B scale and the four different linear category scales, NPEs were converted to the appropriate grade for assessment methods 2 to 6 . These grade data were subsequently converted to the appropriate midpoint value of each grade for analysis. Subsequently, a $t$ test was applied to determine whether an observed difference between the means of the two severity distributions could be attributed to chance. A parametric test was considered appropriate for these data as they were midpoint values on a ratio scale rather than categories with uneven intervals. The aim was to evaluate how a particular scale affected the probability that $\mathrm{H}_{0}$ is rejected when $\mathrm{H}_{0}$ was false. To calculate the probability that $\mathrm{H}_{0}$ is rejected, the simulation procedure outlined above was repeated 10,000 times and a $t$ test was performed each time. The proportion of occasions that $\mathrm{H}_{0}$ was rejected in these 10,000 tests was plotted against population and sample parameters (sample size, difference between population severity means, and magnitude of population standard deviation of the severity mean) for a range of severity population means including 
$1,5,20,30,40$, and 50\%. Also, the additional number of samples needed to obtain the same probability as NPEs for the least good methods was calculated. The algorithm for the calculation is as follows: if comparing two assessment methods (for example, 1 and 2) with an assumed sample size (n) of 5 (for a population severity mean $\left[\mu_{\text {actual }}\right]=20$ ), and the probability of rejecting $\mathrm{H}_{0}$ for assessment method 1 and 2 equals 0.304 and 0.220 , respectively; the additional number of samples required by assessment method 2 to equal the probability of rejecting $\mathrm{H}_{0}$ compared with assessment method 1 is calculated by adding sample observations incrementally by 1 . Thus, when the probability of method 2 of rejecting $\mathrm{H}_{0} \geq 0.304$, the corresponding smallest number of samples for that method will be obtained. Finally, the percent increase in the sample size (\% n) using method 2 compared with assessment method 1 needed to attain the same probability to reject $\mathrm{H}_{0}$ was calculated.

Mixed model analysis of disease assessment data. We analyzed the disease assessment data from field-collected citrus canker-infected grapefruit leaves $(8,9)$ using a mixed model $(30)$ where $Y_{c j p}$ represents the error of estimation for the $j^{\text {th }}$ leaf from the $c^{\text {th }}$ replicate using the $p^{\text {-th }}$ assessment method:

$$
Y_{c j p}=\mu+a_{c}+\tau_{p}+(a \tau)_{c p}+\varepsilon_{c j p}
$$

and $\mu$ is the overall mean, $a_{c}$ is the effect of the $c^{\text {th }}$ replicate, $\tau_{p}$ is the effect of the $p^{\text {th }}$ assessment method, and $(a \tau)_{c p}$ is the replicate $x$ assessment method interaction term. We assumed that the $a_{c}$ and $(a \tau)_{c p}$ are mutually independent, normally distributed random variables. Here, $Y$ was defined as error of estimation. That is, $Y=$ $(E-T) /[T \times(1-T)]^{0.5} . E$ is the estimated disease severity and $T$ is the true disease severity. The difference $E-T$ is scaled by $[T \times(1$ $-T)]^{0.5}$, assuming that the variance function of estimation errors $E-T$ is proportional to that of a binomial distribution. This transformation led to residuals with better variance homogeneity. In contrast to Hartung and Piepho (20), we used the absolute value of $Y$ to obtain the magnitude of the error.

Bootstrap analysis of assessment data. To further test the result of the mixed model analysis, we utilized a bootstrapping method to generate simulated data based on the original rater estimates $(8,9)$. In a bootstrap resampling, 1,000 new samples, each of the same size as the observed data, were drawn with replacement from the observed data. The errors of each assessment method were calculated using each of the 1,000 new samples, yielding a bootstrapped distribution. The mean of these errors for each assessment method was calculated to assess the effect of the different assessment methods. The paired comparisons of an analysis of variance (ANOVA) among the six different assessment methods were used to calculate the number of times there was a significant difference between methods in the 1,000 bootstrapped simulation data sets.

The mixed model analysis was done using SAS (version 9.3, SAS Institute, Cary, NC). The simulation analysis was performed using an $\mathrm{R}$ routine written by the first and second authors. The program codes are available free from the first author.

\section{RESULTS}

Hypothesis testing. A total of 10,000 NPEs simulations per $1 \%$ increment were made between 0 and $50 \%$ severity. The means of the standard deviations of the simulated NPEs were calculated for each sample size group and the mean values of the standard deviations plotted against the range of actual severities for the NPEs (Fig. 1A). The NPEs and H-B scale estimates (Fig. $1 \mathrm{~A}$ and $\mathrm{B}$ ) equate to those in Figure $3 \mathrm{C}$ and D of Bock et al. (7). The means of the standard deviations of groups for a sample size of 2 were consistently smaller compared with the fitted standard deviations, and compared with the standard deviations of the larger group sample sizes. The mean of the standard deviation of the sample sizes $>2$ was generally in close agreement with the fitted rater standard deviation. The simulated H-B scale midpoint data showed a dip associated with the midpoints of the largest interval size ( 25 to $50 \%$ severity); thus, it is over this range that differences in hypothesis testing are most likely to occur using the H-B scale (Fig. 1B). Thus, Bock et al. (7) focused on this range of severities. However, with the remaining assessment methods (Fig. $1 \mathrm{C}$ to $\mathrm{F}$ ), the relationships between the mean standard deviations of the groups and the range of actual severity demonstrated that at low actual severity using the 5 or $10 \%$ category scale (Fig. 1C and $\mathrm{D}$, assessment methods 3 and 4 , respectively), there was a tendency to underestimate the mean standard deviation at severity $<5$ and $10 \%$, respectively. Incorporation of additional categories at severity $<5$ or $<10 \%$ eliminated this tendency (Fig. 1E and F, assessment methods 5 and 6 , respectively) and the means of the standard deviations closely mimicked the fitted standard deviations for the NPEs.

As might be expected, the number of samples affected the probability to reject $\mathrm{H}_{0}$ (when $\mathrm{H}_{0}$ was false) particularly when disease severity was $\leq 5 \%$ (Fig. $2 \mathrm{~A}$ to $\mathrm{F}$ ). As the sample size was increased for all assessment methods, the probability to reject $\mathrm{H}_{0}$ increased (when $\mathrm{H}_{0}$ was false). At sample sizes $\leq 5$, assessment method 4 (10\% category scale) had larger type II errors compared with the other methods (Fig. 2A and B). Thus, using a $10 \%$ scale with equal interval widths was detrimental to the probability to reject $\mathrm{H}_{0}$ when the actual severity was low. However, at higher disease severity $\left(\mu_{\mathrm{A}}=20,30,40\right.$, and $\left.50 \%\right)$, assessment method 2 (the $\mathrm{H}-\mathrm{B}$ scale) had a lower probability to reject $\mathrm{H}_{0}$ when $\mathrm{H}_{0}$ was false compared with the other assessment methods (Fig. 2D to F).

Increasing difference between the population means $\left(\mu_{\Delta}=2\right.$ to $20, n=20$, and $\varphi=5$ ) increased the probability of rejecting $\mathrm{H}_{0}$ for all assessment methods (Fig. 3A to F). However, at disease severities $\leq 5 \%$, use of assessment method 4 (the $10 \%$ scale) had a higher probability of committing type II errors compared with the other assessment methods. But at greater mean disease severities (30 to $50 \%$, Fig. 3D to F), the H-B scale had a lower probability to reject $\mathrm{H}_{0}$ when this hypothesis was false. The other assessment methods closely mimicked NPEs.

As previously noted (7), for each assessment method, when the standard deviation of the severity distribution is large, there is a lower probability to reject $\mathrm{H}_{0}$ when this hypothesis is false (Fig. $4 \mathrm{~A}$ to $\mathrm{F}$ ). The $10 \%$ category scale (assessment method 4 ) had a lower probability of rejecting $\mathrm{H}_{0}$, when $\mathrm{H}_{0}$ was false at population means $\left(\mu_{\mathrm{A}}\right)$ of $\leq 5 \%$ compared with NPEs and other assessment methods (Fig. 4A and B). Furthermore, the 5\% category scale (assessment method 3) had a lower probability of rejecting $\mathrm{H}_{0}$, when $\mathrm{H}_{0}$ was false at population means $\left(\mu_{\mathrm{A}}\right)$ of $\leq 1 \%$ (Fig. $4 \mathrm{~A}$ ). Thus, using an equal interval width of $5 \%$ is not a guarantor of superior estimates of disease compared with NPEs or the other assessment methods. As previously observed, at greater mean disease severities (Fig. 4C to F), the H-B scale (assessment method 2) had a lower probability to correctly reject the $\mathrm{H}_{0}$ compared with all other assessment methods.

A greater sample size can be taken to achieve the same probability as NPEs of rejecting $\mathrm{H}_{0}$, when $\mathrm{H}_{0}$ is false for the least good assessment methods (7). In this case, Figure $2 \mathrm{~A}$ to $\mathrm{F}$ showed that the $10 \%$ category scale and the H-B scale (assessment method 4 and 2 , respectively) had the lowest probability to reject $\mathrm{H}_{0}$. The required increase in sample size $(\% n)$ when using the least good method (assessment method 4 in Figure 5A and B; assessment method 2 in Figure $5 \mathrm{C}$ to $\mathrm{F}$ ) to get a probability of rejecting $\mathrm{H}_{0}$ equal to NPEs was calculated for various presumed population mean disease severities, mean differences, and a fixed standard deviation (Fig. 5A to F). The anticipated increase in sample size using the $10 \%$ category scale is depicted in Figure $5 \mathrm{~A}$ and $\mathrm{B}$, and for the $\mathrm{H}-\mathrm{B}$ scale in Figure 5C to $\mathrm{F}$. Thus, with a population mean of $1 \%$ and assessment made using the $10 \%$ category scale, up to an additional $180 \%$ the number of samples $(n)$ were required to 
obtain the same probability as NPEs (Fig. 5A). Using the H-B scale, an additional $50 \%$ samples were required to attain the same probability to reject the $\mathrm{H}_{0}$ as NPEs when $\mathrm{H}_{0}$ was false.

The ability of the 5\% category scale, and the amended 5 and $10 \%$ category scales (assessment methods 3,5 , and 6) to reject $\mathrm{H}_{0}$ when $\mathrm{H}_{0}$ was false closely mimicked that of the NPEs for mean disease severity. Too many divisions in a category scale might negate the assumed advantages of speed and simplicity offered by a category scale (although the advantages of speed using a category scale have yet to be fully characterized $[11,20])$. Thus we reason that assessment method 6 (the amended $10 \%$ category scale) is superior to other methods for reducing the risk of type II errors and for raters who desire to base their severity estimation on a disease scale for hypothesis testing.

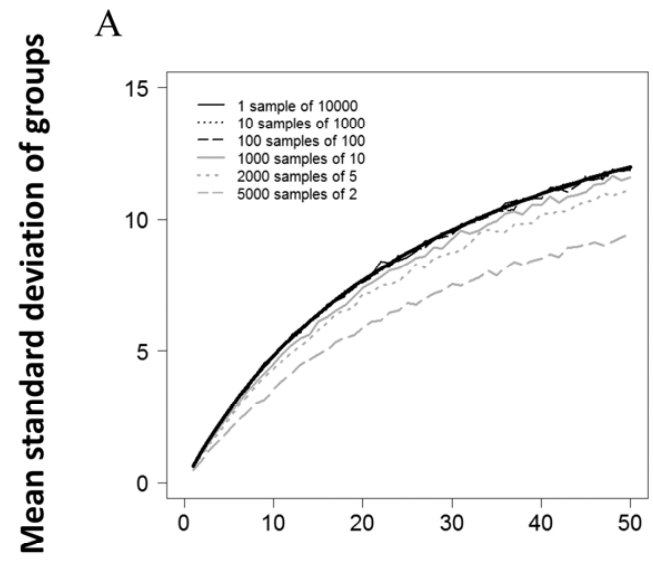

B

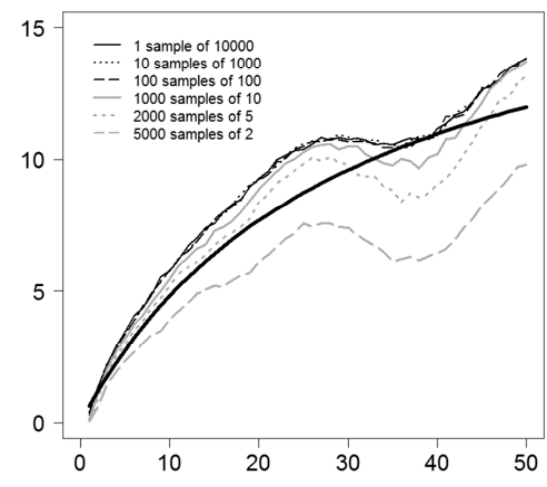

C

D
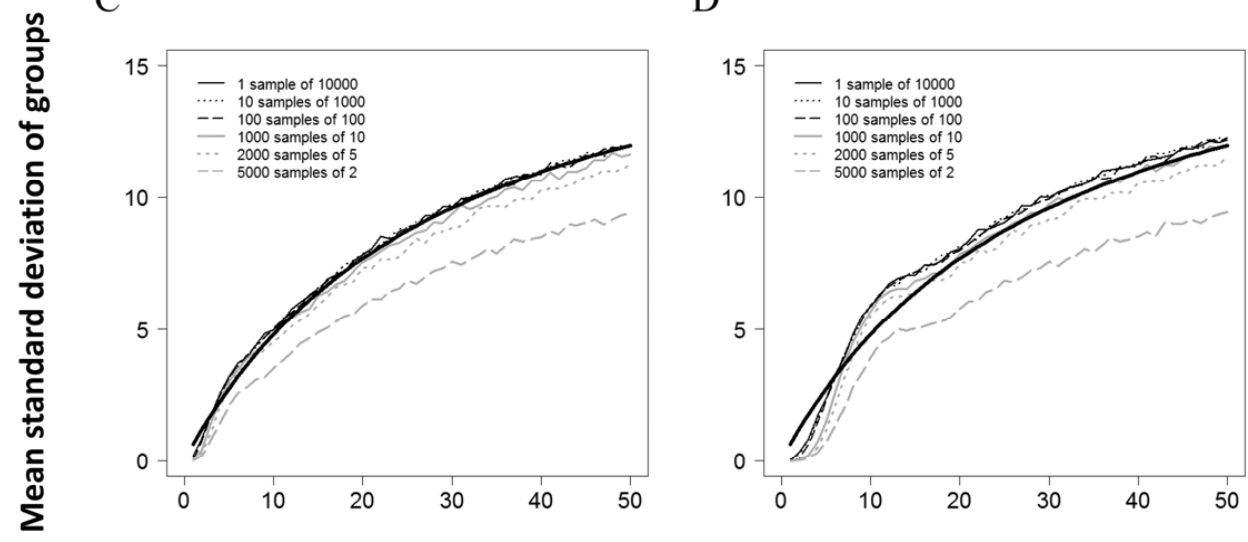

$\mathrm{E}$

F
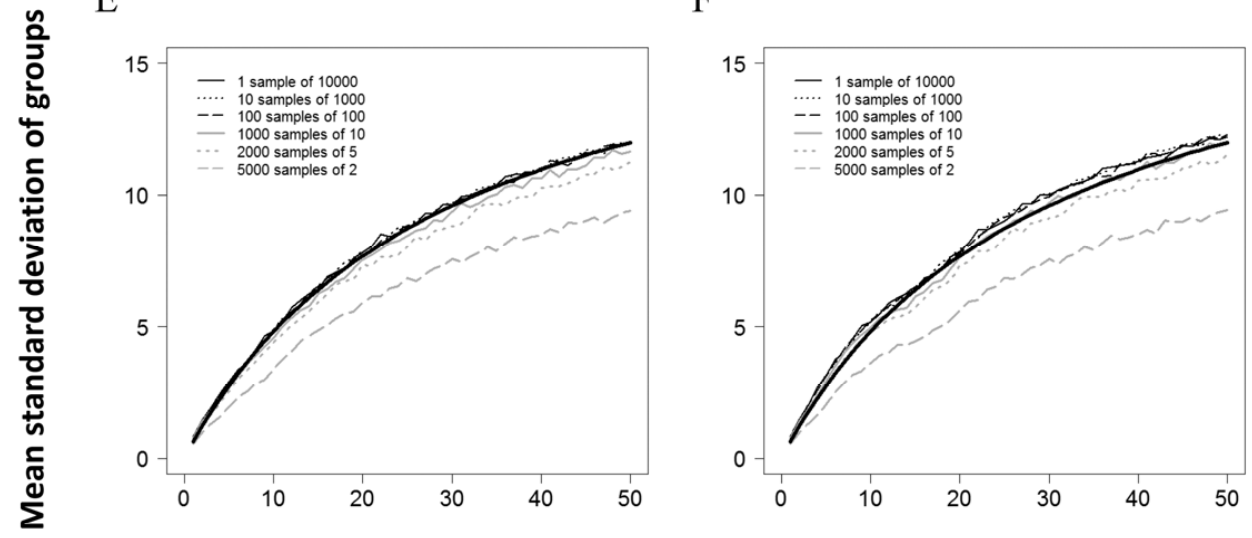

Actual severity (\%)

\section{Actual severity (\%)}

Fig. 1. A, A total of 10,000 nearest percent estimate (NPE) simulations were taken from 0 to $50 \%$ severity in $1 \%$ increments, based on a lognormal distribution assumed to describe the frequency of NPEs of actual disease severities by raters. Subsequently, means of the standard deviations of simulated NPEs were calculated for the groups of different sample sizes using these fixed simulations. B, Data from A, but scaled to assessment method 2 (the H-B scale). C, Data from A, but scaled to assessment method 3 (linear scale [5\%]). D, Data from A, but scaled to assessment method 4 (linear scale [10\%]). E, Data from A, but scaled to assessment method 5 (amended linear scale [5\%]). F, Data from A, but scaled to assessment method 6 (amended linear scale [10\%]). The bold black line is the hyperbolic fit to the actual standard deviation of the severity estimates as described in the Theory and Approaches. 
Mixed model analysis of disease assessment data. The mean errors of estimation using the six different assessment methods based on a mixed model analysis (Table 1) showed that the NPEs had the lowest error (0.097) followed by the amended 5\% category scale (assessment method $5=0.104$ ). The $10 \%$ category scale was least good (assessment method $4=0.175$ ). Differences between the least squared means (Table 2) demonstrated those assessment methods that were equal to NPEs in ability to accurately assess disease. The only method that was equally accurate to NPEs was the amended 5\% scale (assessment method 5). The amended 5\% scale was not different from the amended $10 \%$ scale, but the amended $10 \%$ scale was significantly different from NPEs. The $10 \%$ category scale and the H-B scale were less accurate compared with NPEs. The errors of estimation were ranked (Fig. 6) according to $P$ values from Table 2. The result of the mixed model analysis is consistent with that of hypothesis testing.

Bootstrap analysis of assessment data. The bootstrap analysis verified the mixed model analysis (Tables 3 and 4). The mean error for the different assessment methods based on the bootstrap analysis (Table 3) showed the same trends as those found in the mixed model analysis (Table 1). The paired comparisons of assessment methods (Table 4) based on the ANOVA (which establishes significant differences between assessment methods using the incidence of significant differences between the paired comparisons of the 1,000 bootstrapped simulations) showed that
A

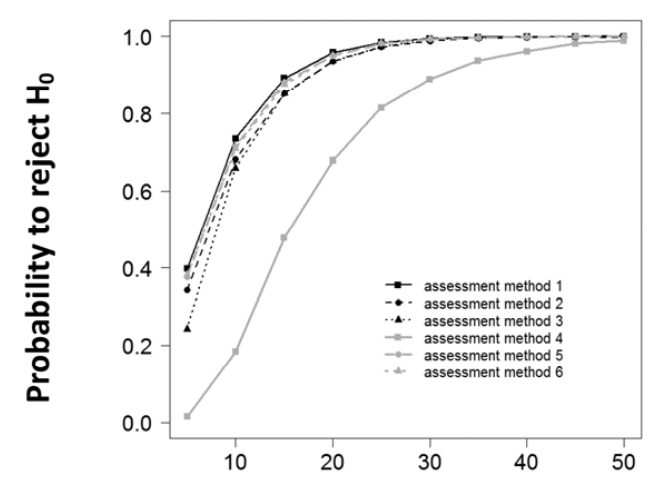

C

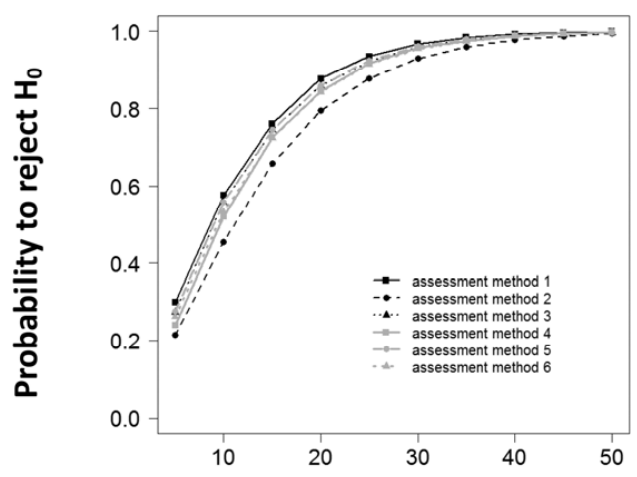

E

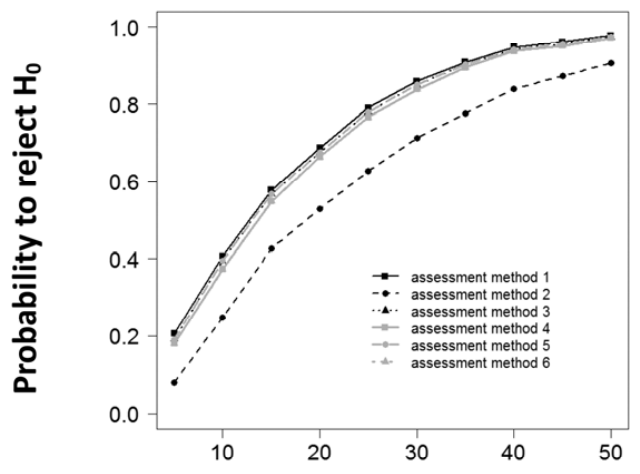

Number of samples $(n)$
B

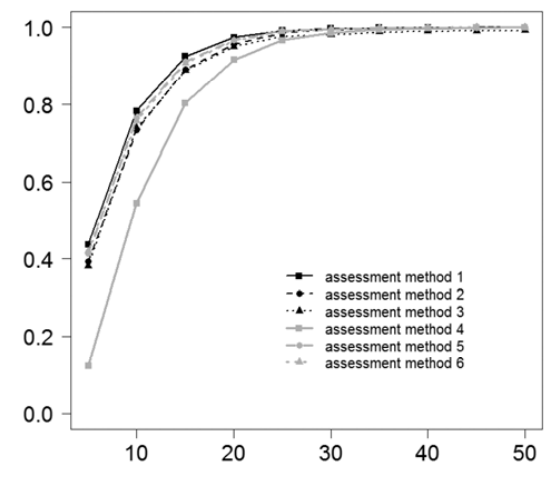

$\mathrm{D}$

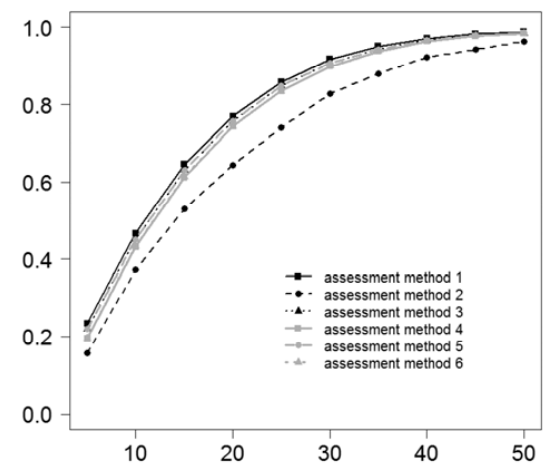

F

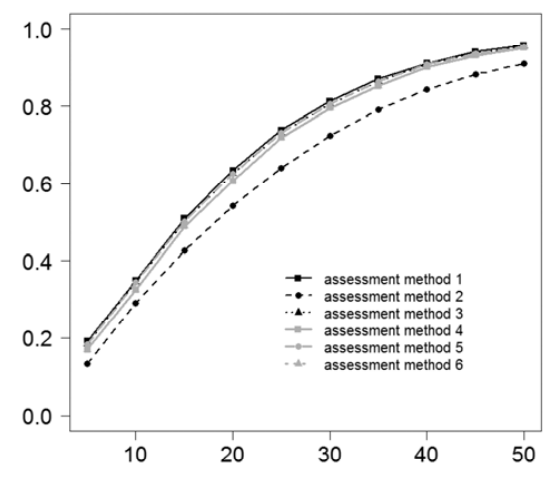

Fig. 2. The relationships between the probability to reject $\mathrm{H}_{0}$ (when this hypothesis is false) and samples size ( $n=5$ to 50$)$ for the different assessment scales at different population means $\left(\mathbf{A}, 1 ; \mathbf{B}, 5 ; \mathbf{C}, 20 ; \mathbf{D}, 30 ; \mathbf{E}, 40\right.$, and $\mathbf{F}, 50 \%$ disease severity). The difference between the population means $\left(\mu_{\Delta}\right)$ is assumed to be 10 , $\varphi=5$, with significance at $P=0.05$. Assessment method 1: nearest percent estimates; method 2: H-B scale; method 3: linear scale (5\%); method 4: linear scale (10\%); method 5: amended linear scale (5\%); and method 6: amended linear scale (10\%). 
there were no significant differences among assessment methods $1,3,5$, and 6 . This result further confirms the conclusion from the mixed model analysis of the actual disease severity data that use of both the $10 \%$ category scale and the H-B scale resulted in data that were less accurate compared with those using NPEs.

\section{DISCUSSION}

Based on a known distribution of disease assessment from experienced raters, the results demonstrate that category scales with certain characteristics might be more appropriate than others for obtaining accurate, precise data that will minimize the risk of type II errors (the failure to reject $\mathrm{H}_{0}$ when $\mathrm{H}_{0}$ is false). This has previously been demonstrated for the H-B scale (7), the shortcomings of which have been described (34); however, other scale types had not previously been investigated using a simulation approach. Based on the results of this study, a disease assessment category scale should be sensitive to low disease severity (1 to $10 \%$ ) by incorporating additional categories to account for disease severity $\leq 5 \%$. Category intervals in the midrange should not
A

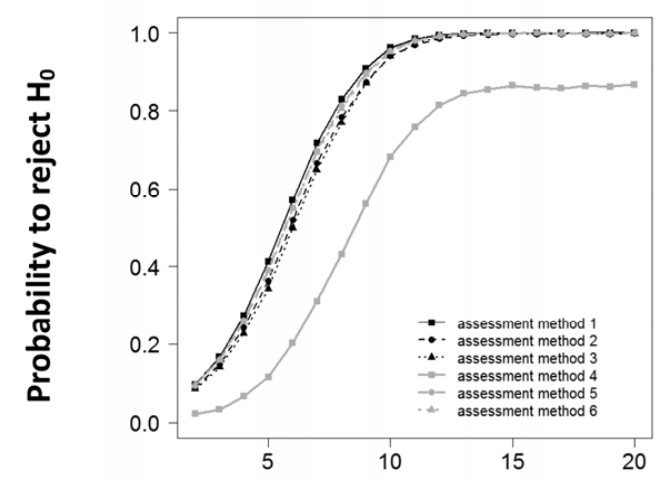

$\mathrm{C}$

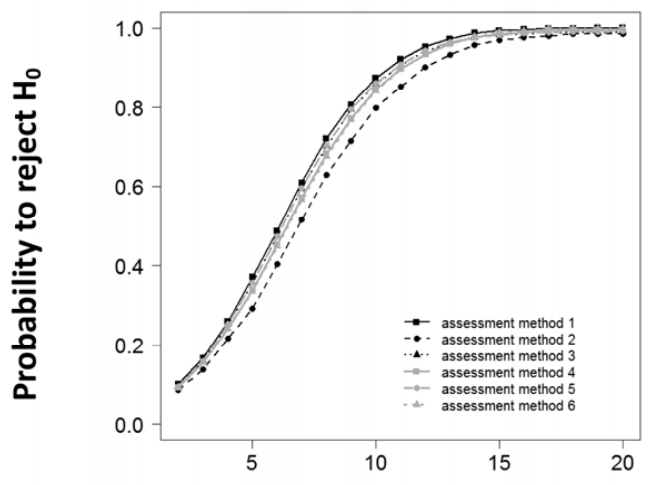

$\mathrm{E}$

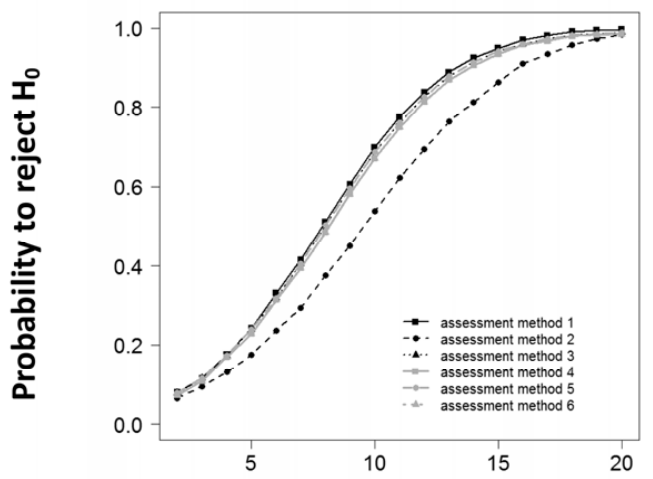

Difference in population means $\left(\mu_{\Delta}\right)$
B

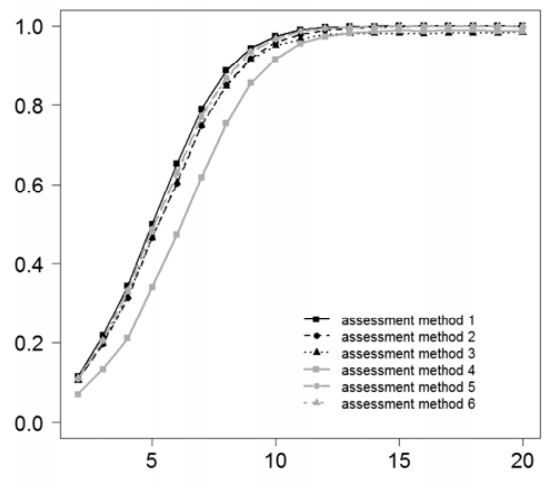

$\mathrm{D}$

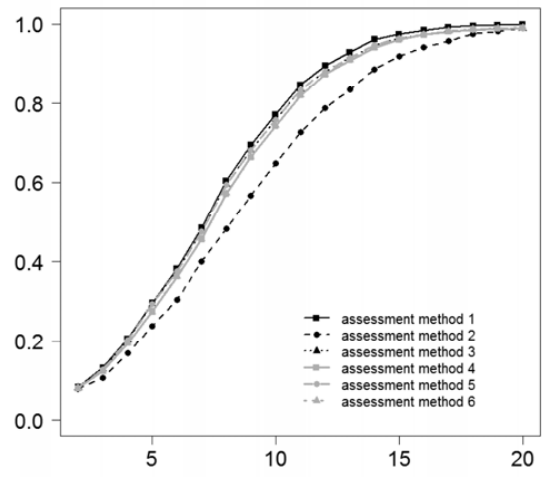

F

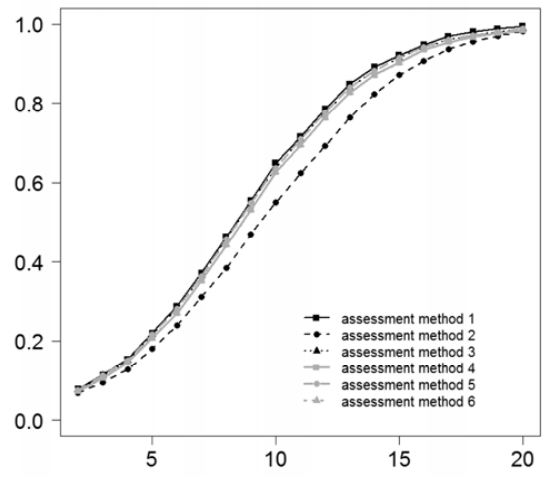

Difference in population means $\left(\mu_{\Delta}\right)$

Fig. 3. The relationship between the differences in population means $\left(\mu_{\Delta}=2\right.$ to 20$)$ and the probability of rejecting the null hypothesis $\left(\mathrm{H}_{0}\right)$ at a sample size $(n)$ of 20 for various population mean disease severities $(\mathbf{A}, 1 ; \mathbf{B}, 5 ; \mathbf{C}, 20 ; \mathbf{D}, 30 ; \mathbf{E}, 40$, and $\mathbf{F}, 50 \%$ disease severity). The assumed $\varphi=5$, with significance at $P=0.05$. Assessment method 1: nearest percent estimates; method 2: H-B scale; method 3: linear scale (5\%); method 4: linear scale (10\%); method 5: amended linear scale $(5 \%)$; and method 6: amended linear scale (10\%). 
exceed $10 \%$, and $5 \%$ categories will more often provide more accurate and precise data at a smaller sample size.

In this study the probability of committing a type II error using assessment methods 3 to 6 were similar to NPEs provided the range of severities was 20 to $50 \%$ (although not shown in the article, the actual severity of $10 \%$ was simulated [Supplementary Figure 1] and the result was as expected). Furthermore, the H-B scale does not have a greater type II error rate compared with other scales at low actual severities (1 to 5\%), but the risk of type II error rates increases as the mean disease severity increases to 20 to $50 \%$ severity (Figs. 2, 3, and 4). However, scales with equal interval widths (5 or $10 \%$ ) tend to have a greater risk of type II error at low disease severities $(\leq 5 \%)$. Thus, our results are in contrast to those of Hartung and Piepho (20) who found that a $5 \%$ interval scale was equivalent (and even performed better) compared with a $1 \%$ interval scale. But an amended category scale with additional intervals at $<5 \%$, as suggested by Nita et al. (32), did have a type II error rate equivalent to NPEs in our study. Hartung and Piepho (20) also found that a category scale (which they called an ordinal scale, which it is not $[10,31])$ with logarithmically spaced intervals was inferior to the percent scales.
A

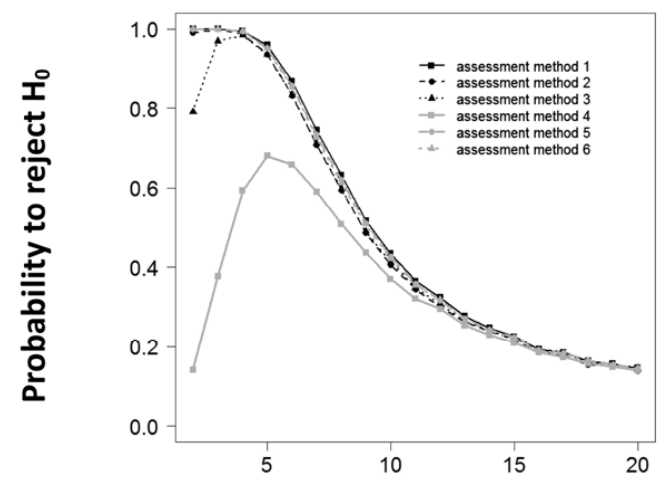

$\mathrm{C}$

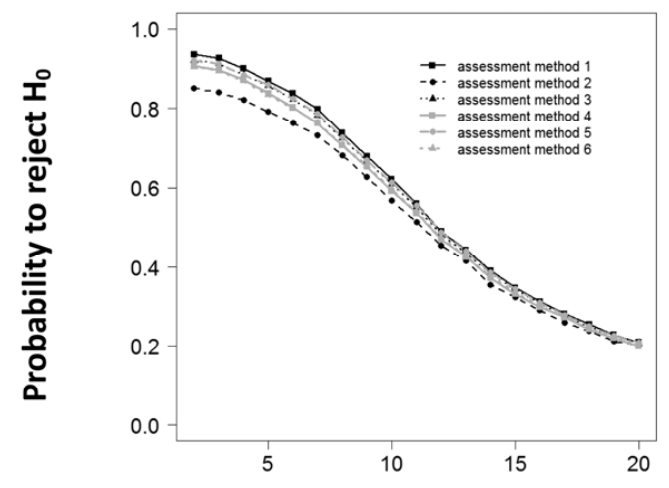

E

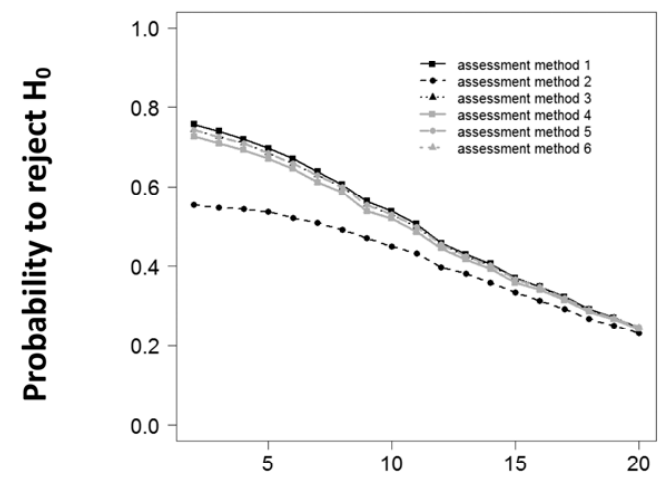

Population standard deviation $(\varphi)$
B

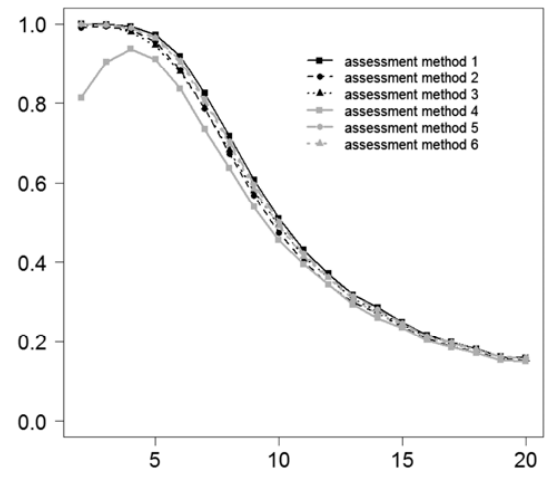

D

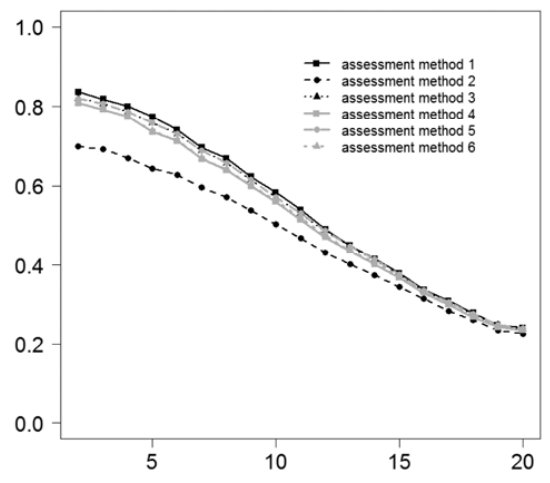

F

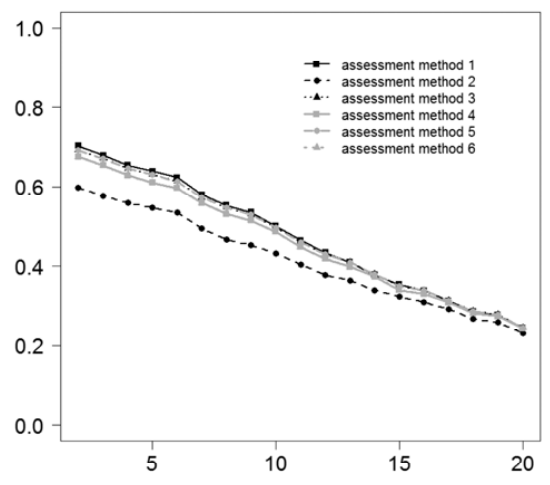

Population standard deviation $(\varphi)$

Fig. 4. The relationship between the population disease severity standard deviation $(\varphi=2$ to 20$)$ and the probability of rejecting the null hypothesis $\left(\mathrm{H}_{0}\right)$ at a sample size $(n)$ of 20 for various mean population disease severities $\left(\mathbf{A}, 1 ; \mathbf{B}, 5 ; \mathbf{C}, 20 ; \mathbf{D}, 30 ; \mathbf{E}, 40\right.$, and $\mathbf{F}, 50 \%$ disease severity). The assumed $\mu_{\Delta}=10$, with significance at $P=0.05$. Assessment method 1: nearest percent estimates; method 2: H-B scale; method 3: linear scale (5\%); method 4: linear scale (10\%); method 5: amended linear scale (5\%); and method 6: amended linear scale (10\%). 
Others have developed category scales and explored the characteristics, applicability, and use of these scales and the need for them to be sensitive to actual disease severity (and distribution of disease severity) that is observed in the field in particular pathosystems $(20,21,24,26,27-29,43)$. Much of the reasoning for nonlinear, logarithmic type category scales that has been suggested is based on the nonexistent Weber-Fechner law referred to by Horsfall and Barratt (24) (“...the Weber-Fechner law which states that visual acuity depends on the logarithm of the intensity of the stimulus" [23]). There are actually two distinct laws $(10,34)$, and subsequent work has demonstrated that whereas
Weber's law holds true (that states the physical size of a just noticeable difference is a constant proportion of the value of the standard for a given dimension), Fechner's does not (which adds that the subjective value is a logarithmic function of the physical value) $(2,5,10,22,32,34)$. Based on the results of this study, and other studies $(6,7,32,34)$, linear category scales with sensitivity to low severity of disease are preferable to nonlinear category scales for assessing disease severity.

The mixed model and the bootstrap analyses both confirmed the results of the simulation studies. Although the error for assessment method 6 (amended 10\% category scale) was slightly

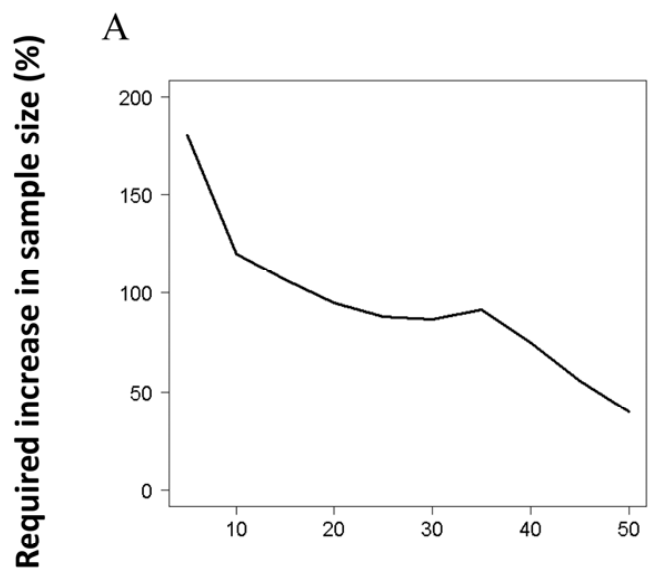

B

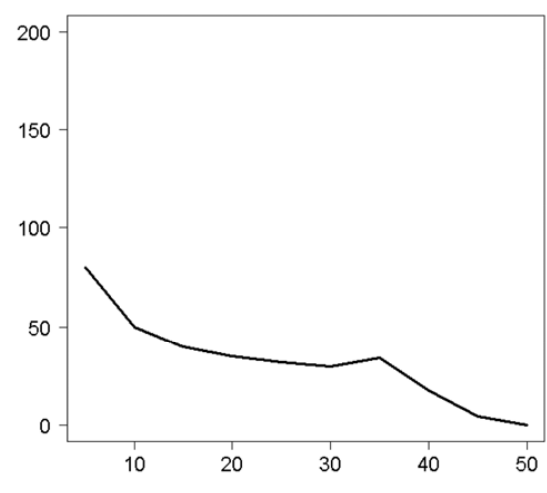

$\mathrm{C}$

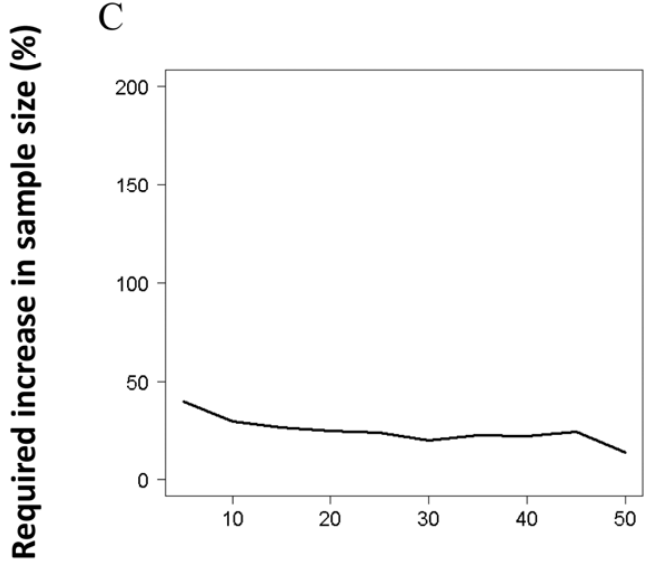

$\mathrm{D}$

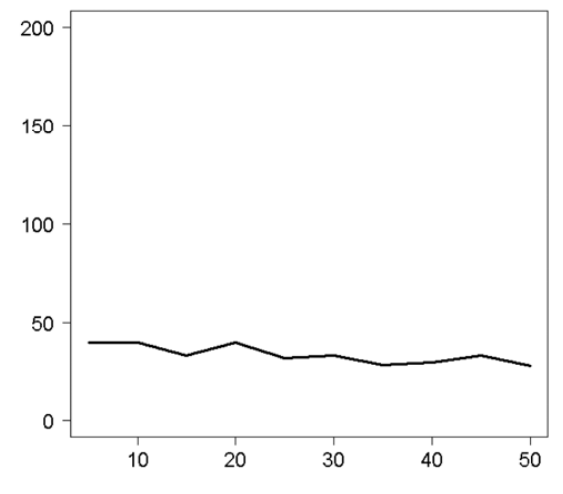

F

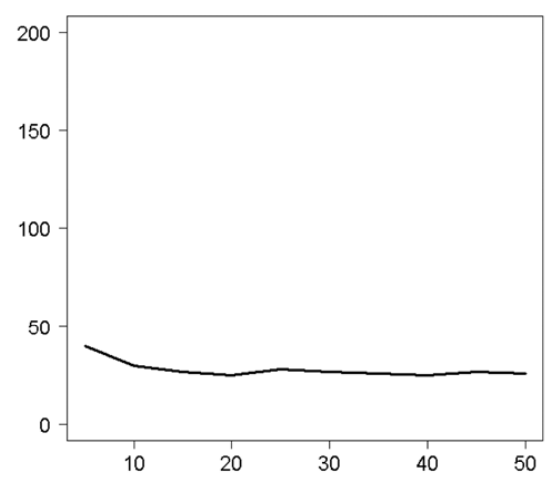

Number of samples $(n)$

Fig. 5. The required increase in sample size $(\% n)$ to get a probability of rejecting $\mathrm{H}_{0}$ with the least good method (assessment method 4 in Figure 5A and B; assessment method 2 in Figure 5C to F) equal to that of nearest percent estimates at a given sample size for various mean population disease severities (A, 1 ; $\mathbf{B}, 5$; $\mathbf{C}, 20 ; \mathbf{D}, 30 ; \mathbf{E}, 40$, and $\mathbf{F}, 50 \%$ disease severity). The assumed difference between the population means $\left(\mu_{\Delta}\right)=10, \varphi=5$, with significance at $P=0.05$. 
greater than that for assessment method 5 (amended 5\% category scale) by mixed model analysis, the discrepancy was not significant. In addition, there are fewer interval divisions in assessment method 6 . Thus, assessment method 6 (amended $10 \%$ category scale) can be considered a good choice for assessing disease at least over the range of severities from 1 to $50 \%$. Moreover, the results of the bootstrap analysis were in agreement with those of the mixed model analysis.

Our results were based on the assumption that equations 1 and 2 were true (that the relationship between actual disease and rater estimates is linear, and that a hyperbolic function described the relationship between the standard deviation $(\sigma)$ of the rater mean NPE and actual disease, respectively). From previous studies $(8,18,32,34,41)$, all evidence to date demonstrates a linear relationship between visually estimated and actual disease severity. Thus, the rationale for equation 1 holds true. However, the nature of the relationship between the variance and the magnitude of the actual value has not been fully explored or established. Nonconstancy of variance with magnitude of actual disease is widely reported $(9,17,18,20,21)$. For the data used in this analysis, the range of disease severity was 0 to $60 \%$. If the range of disease severity on leaves was 50 to $100 \%$, the relationship for equation 2 would be different as the standard deviation would almost certainly decline toward zero at $100 \%$ severity. In this respect, our conclusions may not always hold at severity $>50 \%$. However, most often plant disease is present at severity $<50$ to $60 \%$ (28) (leaves often abscise if disease becomes too severe, making it difficult to obtain these samples), so the data presented here are of great value to the range of disease most often observed in the field for many pathosystems. A full range of disease severities from 0 to $100 \%$ could be generated using one of the computerbased disease assessment training tools $(33,35)$, as used by Hartung and Piepho (20), which would be useful for future studies exploring use of different disease assessment methods.

Although many studies have described nonconstancy of variance associated with increasing magnitude of actual disease, Nita et al. (32) and Nutter and Esker (34) found little effect of

TABLE 1. The mean estimation errors among the different assessment methods for the rater assessments of field-collected citrus canker-infected grapefruit leaves

\begin{tabular}{lcccccc}
\hline & \multicolumn{6}{c}{ Assessment method $^{\mathrm{a}}$} \\
\cline { 2 - 7 } & 1 & 2 & 3 & 4 & 5 & 6 \\
\hline Mean error & 0.097 & 0.123 & 0.111 & 0.175 & 0.104 & 0.110 \\
\hline
\end{tabular}

a Assessment method 1: nearest percent estimates; method 2: Horsfall-Barratt scale; method 3: linear scale (5\%); method 4: linear scale (10\%); method 5: amended linear scale (5\%); and method 6: amended linear scale (10\%). magnitude of actual disease on estimation error. Bock et al. (10) commented that apart from contrasting results between the variance of the estimate and the actual disease, these differences might be due in part to how the various studies were conducted, the raters, and how the data were processed that might affect conclusions regarding the relationships (including use of individual, multiple rater, or averaged rater data). In our study, there are particularly small means of the standard deviations of groups for small sample sizes $(n=2)$ compared with the larger sample sizes (Fig. 1). Thus, the simulation verified the fact that the characteristics of the variance of the estimate can depend on whether the actual disease is compared with an individual's estimates, raters as a group, or the mean values.

In addition to aiding development of category scales based on the performance observed in this study using the amended 5 and $10 \%$ category scales, which performed as well as NPEs, the information will also be useful in the design of standard area diagrams (SADs). To date, SADs have most often been logarithmically based $(1,3,19)$, although there are examples of SADs with a stated basis of a linear scale to account for the psychophysical

\section{Assessment method}

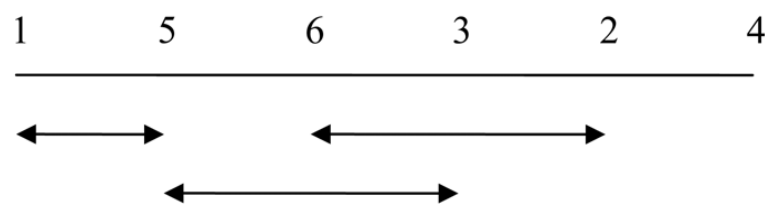

Fig. 6. Groups of assessment methods that were not significantly different from each other based on mean errors indicated by arrows for the rater assessments of field-collected citrus canker-infected grapefruit leaves. The arrows under the assessment methods are drawn according to the $P$ values given in Table 2, indicating the differences based on the least squares means for each paired comparison of methods that are not significant.

TABLE 3. Bootstrap analysis of the rater assessments of field-collected citrus canker-infected grapefruit leaves showing the means of the estimation errors for the different assessment methods

\begin{tabular}{ccccccc}
\hline & \multicolumn{6}{c}{ Assessment method $^{\mathrm{a}}$} \\
\cline { 2 - 7 } & 1 & 2 & 3 & 4 & 5 & 6 \\
\hline Mean error & 0.090 & 0.114 & 0.103 & 0.162 & 0.096 & 0.102 \\
\hline
\end{tabular}

a Assessment method 1: nearest percent estimates; method 2: Horsfall-Barratt scale; method 3: linear scale (5\%); method 4: linear scale (10\%); method 5: amended linear scale (5\%); and method 6: amended linear scale (10\%).

TABLE 2. The mean estimation errors among the mixed model analysis for the rater assessments of field-collected citrus canker-infected grapefruit leaves ${ }^{\mathrm{a}}$

\begin{tabular}{|c|c|c|c|c|c|c|}
\hline \multirow{2}{*}{\multicolumn{2}{|c|}{ Comparison of the paired methods }} & \multicolumn{5}{|c|}{ Least squares means comparisons } \\
\hline & & \multirow{2}{*}{$\frac{\text { Estimate }}{-0.02570}$} & \multirow{2}{*}{$\frac{\text { Standard error }}{0.004806}$} & \multirow{2}{*}{$\frac{\mathrm{df}}{5}$} & \multirow{2}{*}{$\frac{t \text { value }}{-5.35}$} & \multirow{2}{*}{$\frac{P>|t|}{0.0031}$} \\
\hline 1 & 2 & & & & & \\
\hline 1 & 3 & -0.01398 & 0.004588 & 5 & -3.05 & 0.0285 \\
\hline 1 & 4 & -0.07764 & 0.008484 & 5 & -9.15 & 0.0003 \\
\hline 1 & 5 & -0.00657 & 0.003407 & 5 & -1.93 & 0.1116 \\
\hline 1 & 6 & -0.01283 & 0.004004 & 5 & -3.20 & 0.0239 \\
\hline 2 & 3 & 0.01172 & 0.005998 & 5 & 1.95 & 0.1081 \\
\hline 2 & 4 & -0.05194 & 0.009215 & 5 & -5.64 & 0.0024 \\
\hline 2 & 5 & 0.01913 & 0.005623 & 5 & 3.40 & 0.0192 \\
\hline 2 & 6 & 0.01288 & 0.005801 & 5 & 2.22 & 0.0772 \\
\hline 3 & 4 & -0.06366 & 0.006826 & 5 & -9.33 & 0.0002 \\
\hline 3 & 5 & 0.007407 & 0.004145 & 5 & 1.79 & 0.1340 \\
\hline 3 & 6 & 0.001154 & 0.004680 & 5 & 0.25 & 0.8151 \\
\hline 4 & 5 & 0.07107 & 0.008443 & 5 & 8.42 & 0.0004 \\
\hline 4 & 6 & 0.06482 & 0.008303 & 5 & 7.81 & 0.0006 \\
\hline 5 & 6 & -0.00625 & 0.003213 & 5 & -1.95 & 0.1092 \\
\hline
\end{tabular}

a Highlighted rows are not statistically significant (assuming significance at $P=0.05$ ). 
laws defining the 'just noticeable difference' $(37,40,45)$. The Rios et al. (40) study had 10 SADs diagrams representing 0.1, 1, 5, 10, $22,32,42,52,62$, and $72 \%$ blast severity. This SAD design conforms to the amended $10 \%$ category scale which performed as well as NPEs in the current study. Is there any difference in the accuracy or precision of the estimate if the SADs are comprised of a linear or logarithmic series? This too is an area for future studies.

Although in most cases where treatment comparisons are being made, or epidemiological studies are being undertaken NPEs are preferable and will reduce the risk of a type II error compared with most category scales $(7,14,43)$, there are still some studies in the disciplines of plant pathology and plant breeding where nonratio type scales have continued application and do not appear to detract from the precision of the data. Nonlinear category or ordinal-type scales are commonly used for plant breeding purposes and have been used and recently compared with the percent scale for quantitative trait loci (QTL) mapping (38). Although Poland and Nelson (38) call their 9-category scale an ordinal scale, it is in fact a logarithmic category or interval-type scale $(10,31)$. Clearly scale type identification remains an issue. In the Poland and Nelson study (38) there were really no effects of scale type (category versus percent [NPE]) in identifying the location and number of QTLs in a mapping population of maize infected with Setosphaeria turcica, although whether there might be an effect of category scale type (compared with a true ordinal scale or NPEs) has not been established. It is worth mentioning that logarithmic H-B-type scales have been used for other purposes beyond rating disease, including studies in entomology $(4,36)$, phytotoxicity studies (15), and to study the effects of environmental pollutants on plant health (13). The relevance of these results will be applicable to research where category scales are used to represent intervals on a ratio scale.

Linear category scales with 5 or $10 \%$ category intervals and additional grades at $\leq 5 \%$ severity appear to be equivalent to NPEs for hypothesis testing. In this work, we used both hypothesis testing and a mixed model analysis to compare different category scales for estimating disease severity. In addition to using these two approaches, the calculation of accuracy, precision, agreement and reliability have been used in many studies comparing rating scales $(6,8,9,11,12,32)$. Most of the results from these studies compare well with the results of the simulation approach. However, it would be both interesting and useful to compare the pros and cons of these different approaches in establishing the value of different assessment methods.

TABLE 4. Comparisons of the paired assessment methods based on the analysis of variance

\begin{tabular}{ccc}
\hline Comparison of the paired methods & Proportion $^{\mathrm{a}}$ \\
\hline 1 & 2 & 0.734 \\
1 & 3 & 0.007 \\
1 & 4 & 1.000 \\
1 & 5 & 0.000 \\
1 & 6 & 0.001 \\
2 & 3 & 0.019 \\
2 & 4 & 0.999 \\
2 & 5 & 0.185 \\
2 & 6 & 0.028 \\
3 & 4 & 1.000 \\
3 & 5 & 0.000 \\
3 & 6 & 0.000 \\
4 & 5 & 1.000 \\
4 & 6 & 1.000 \\
5 & 6 & 0.000 \\
\hline
\end{tabular}

a The proportion represents the number of times significant differences occurred between the paired comparisons in the 1,000 bootstrapped simulations. Assuming $P=0.05$, the comparisons in the rows highlighted are not statistically significant.

\section{ACKNOWLEDGMENTS}

We thank F. van den Bosch and S. Parnell at Rothamsted Research, and F. Ferrandino at the Connecticut Agricultural Experiment Station for several useful discussions on disease assessment and possible approaches to explore the relationships between scale types.

\section{LITERATURE CITED}

1. Andrade, G. C. G., Alfenas, A. C., Mafia, R. G., Maffia, L. A., and Gonçalves, R. C. 2005. Diagrammatic scale for assessment of eucalyptus leaf spot severity caused by Quambalaria eucalypti. Fitopatol. Bras. 30:504-509.

2. Baird, J. C., and Norma, E. 1978. Fundamentals of Scaling and Psychophysics. Wiley, New York.

3. Belasque Junior, J., Bassanezi, R. B., Spósito, M. B., Ribeiro, L. M., Jesus de Júnior, W. C., and Amorim, L. 2005. Escalas diagramáticas para avaliação da severidade do cancro cítrico. Fitopatol. Bras. 30:387-393.

4. Bergh, J. C. 2001. Ecology and aerobiology of dispersing citrus rust mites (Acari: Eriophyidae) in central Florida. Environ. Entomol. 30:318-326.

5. Birnbaum, M. H. 1994. Psychophysics. Pages 641-650 in: Encyclopedia of Human Behavior, Vol. 3. V. S. Ramachandran, ed. Academic Press, San Diego.

6. Bock, C. H., Gottwald, T. R., Parker, P. E., Cook, A. Z., Ferrandino, F., Parnell, S., and van den Bosch, F. 2009. The Horsfall-Barratt scale and severity estimates of citrus canker. Eur. J. Plant Pathol. 125:23-38.

7. Bock, C. H., Gottwald, T. R., Parker, P. E., Ferrandino, F., Welham, S., van den Bosch, F., and Parnell, S. 2010. Some consequences of using the Horsfall-Barratt scale for hypothesis testing. Phytopathology 100:10311041.

8. Bock, C. H., Parker, P. E., Cook, A. Z., and Gottwald, T. R. 2008. Visual rating and the use of image analysis for assessing different symptoms of citrus canker on grapefruit leaves. Plant Dis. 92:530-541.

9. Bock, C. H., Parker, P. E., Cook, A. Z., and Gottwald, T. R. 2008. Characteristics of the perception of different severity measures of citrus canker and the relationships between the various symptom types. Plant Dis. 92:927-939.

10. Bock, C. H., Poole, G. H., Parker, P. E., and Gottwald, T. R. 2010. Plant disease severity estimated visually, by digital photography and image analysis, and by hyperspectral imaging. Crit. Rev. Plant Sci. 29:59-107.

11. Bock, C. H., Wood, B. W., and Gottwald, T. R. 2013. Pecan scab severity-Effects of assessment methods. Plant Dis. 97:675-684.

12. Bock, C. H., Wood, B. W., van den Bosch, F., Parnell, S., and Gottwald, T. R. 2013. The effect of Horsfall-Barratt category size on the accuracy and reliability of estimates of pecan scab severity. Plant Dis. 97:797-806.

13. Bussotti, F., Schaub, M., Cozzi, A., Krauchi, N., Ferretti, M., Novak, K., and Skelly, J. M. 2003. Assessment of ozone visible symptoms in the field: Perspectives of quality control. Environ. Pollut. 125:81-89.

14. Christ, B. J. 1991. Effect of disease assessment method on ranking potato cultivars for resistance to early blight. Plant Dis. 75:353-356.

15. Copes, W. E., Chastagner, G. A., and Hummel, R. L. 2003. Toxicity responses of herbaceous and woody ornamental plants to chlorine and hydrogen dioxides. Online. Plant Health Progress doi:10.1094/PHP-20030311-01-RS

16. Danielsen, S., and Munk, L. 2004. Evaluation of disease assessment methods in quinoa for their ability to predict yield loss caused by downy mildew. Crop Prot. 23:219-228.

17. Forbes, G. A., and Jeger, M. J. 1987. Factors affecting the estimation of disease intensity in simulated plant structures. Z. Pflanzenkrankh. Pflanzenschutz 94:113-120.

18. Forbes, G. A., and Korva, J. T. 1994. The effect of using a HorsfallBarratt scale on precision and accuracy of visual estimation of potato late blight severity in the field. Plant Pathol. 43:675-682.

19. Godoy, C. V., Carneiro, S. M. T. P. G., Iamauti, M. T., Dalla Pria, M., Amorim, L., Berger, R. D., and Bergamin Filho, A. 1997. Diagrammatic scales for bean disease: Development and validation. Z. Pflkrankh. Pflschutz. Pfanzen. 104:336-345.

20. Hartung, K., and Piepho, H. P. 2007. Are ordinal rating scales better than percent ratings? A statistical and "psychological" view. Euphytica 155:15-26.

21. Hau, B., Kranz, J., and Konig, R. 1989. Fehler beim Schätzen von Befallsstärken bei Pflanzenanzenkrankheiten. Z. Pflanzenkrankh. Pflanzenschutz 96:649-674.

22. Hebert, T. T. 1982. The rationale for the Horsfall-Barratt plant disease assessment scale. Phytopathology 72:1269.

23. Horsfall, J. G. 1945. Fungicides and their action. Ann. Crypto. Phytopathol. Vol II. Chronica Botanica, Waltham, MA.

24. Horsfall, J. G., and Barratt, R. W. 1945. An improved grading system for measuring plant disease. (Abstr.) Phytopathology 35:655. 
25. Kao, T. C., Sparling, Y., and Rochon, J. 2003. Mixed-effect models to assess consistency and reliability across multiple evaluations. J. Biopharm. Stat. 13:539-548.

26. Koch, H., and Hau, B. 1980. Ein psychologischer aspect beim schatzen von pflanzenkrankheiten. Z. Pflkrankh. Pflschutz 87:587-593.

27. Kranz, J. 1970. Schätzklassen für Krankheitsbefall. Phytopathol. Z. 69:131-139.

28. Kranz, J. 1977. A study on maximum severity in plant disease. Travaux dédiés à G. Viennot-Bourgin, 16:9-73.

29. Kranz, J. 1988. Measuring plant disease. Pages 35-50 in: Experimental Techniques in Plant Disease Epidemiology. J. Kranz and J. Rotem, eds. Springer-Verlag, New York.

30. Littell, R. C., Milliken, G. A., Stroup, W. W., and Wolfinger, R. D. 1996. SAS System for Mixed Models. SAS Institute Inc., Cary, NC.

31. Madden, L. V., Hughes, G., and van den Bosch, F. 2007. The Study of Plant Disease Epidemics. American Phytopathological Society, St. Paul, MN

32. Nita, M., Ellis, M. A., and Madden, L. V. 2003. Reliability and accuracy of visual estimation of Phomopsis leaf blight of strawberry. Phytopathology 93:995-1005.

33. Nutter, F. W., Jr. 1997. Disease severity assessment training. Pages 1-7 in: Exercises in Plant Disease Epidemiology. L. F. Francl and D. A. Neher, eds. American Phytopathological Society, St. Paul, MN.

34. Nutter, F. W., Jr., and Esker, P. D. 2006. The role of psychophysics in phytopathology: The Weber-Fechner law revisited. Eur. J. Plant Pathol. 114:199-213.

35. Nutter, F. W., Jr., and Litwiller, D. 1998. A computer program to generate standard area diagrams to aid raters in assessing disease severity. (Abstr.) Phytopathology 88(suppl.):S117.

36. Pernezney, K., Nuessley, G., and Stall, W. 2003. Integrated pest manage- ment for Florida snap beans. Pamphlet PPP37, IFAS, University of Florida, Gainesville, FL.

37. Pethybridge, S. J., Hay, F. S., and Wilson, C. R. 2004. Pathogenicity of fungi commonly isolated from foliar disease in Tasmanian pyrethrum crops. Aust. Plant Pathol. 33:441-444.

38. Poland, J. A., and Nelson, R. J. 2011. In the eye of the beholder: The effect of rater variability and different rating scales on QTL mapping. Phytopathology 101:290-298.

39. Quan, H., and Shih, W. 1996. Assessing reproducibility by the withinsubject coefficient of variation with random effects models. Biometrics 52:1195-1203.

40. Rios, J. A., Debona, D., Duarte, H. S. S., and Rodrigues, F. A. 2013. Development and validation of a standard area diagram set to assess blast severity on wheat leaves. Eur. J. Plant Pathol. 136:603-611.

41. Sherwood, R. T., Berg, C. C., Hoover, M. R., and Zeiders, K. E. 1983. Illusions in visual assessment of Stagonospora leaf spot of orchard grass. Phytopathology 73:173-177.

42. Slopek, S. W. 1989. An improved method of estimating percent leaf area diseases using a 1 to 5 disease assessment scale. Can. J. Plant Pathol. 11:381-387.

43. Todd, L. R., and Kommedahl, T. 1994. Image analysis and visual estimates for evaluating disease reactions of corn to Fusarium stalk rot. Plant Dis. 78:876-878.

44. Vereijssen, J., Schneider, J. H. M., Termorshuizen, A. J., and Jeger, M. J. 2003. Comparison of two disease assessment methods for assessing Cercospora leaf spot in sugar beet. Crop Prot. 22:201-209.

45. Yadav, N. V. S., de Vos, S. M., Bock, C. H., and Wood, B. W. 2013. Development and validation of standard area diagrams to aide assessment of pecan scab symptoms on pecan fruit. Plant Pathol. 62:325-335. 